\title{
Topographic distribution of gastritis in heavy pigs investigated by a geographic information system approach
}

\author{
Ernesto Pascotto, ${ }^{1}$ Diego Capraro, ${ }^{2}$ Paolo Tomè, ${ }^{2}$ Mauro Spanghero² \\ ${ }^{1}$ Local Health Unit, Asolo (TV); ${ }^{2}$ Department of Agri-Food, Environmental and Animal \\ Sciences, University of Udine, Udine, Italy
}

\begin{abstract}
The aim of this paper was to determine the topographic distribution of gastritis lesions in pigs through an open source geographic information system (GIS) software analysis. The stomachs of 146 Italian heavy pigs were collected at slaughter and subjected to macroscopic pathological examination of the internal mucosa. A total of 623 lesions were either classified as hyperplastic or follicular (97\%) with the remaining minority of lesions categorised as atrophic and simple. The hyperplastic gastritis lesions had an average surface of $77.8 \mathrm{~cm}^{2}$ and were mainly located in an oval shaped area of the fundus region of the stomach near the Curvatura ventriculi major. The follicular gastritis lesions had generally a smaller surface $\left(40.3 \mathrm{~cm}^{2}\right)$ and were concentrated in two distinct small areas of the pyloric region. The GIS analysis provided the opportunity to produce useful maps showing the distribution and characteristics of gastritis in pigs.
\end{abstract}

Correspondence: Mauro Spanghero, Department of Agri-Food, Environmental and Animal Sciences, University of Udine, via Sondrio 2/A, 33100 Udine, Italy.

Tel: +39.432 .558193 - Fax: +39.432 .558199 .

E-mail: mauro.spanghero@uniud.it

Key words: Pigs; Gastritis; Topographic distribution; Geographic information system; Italy.

Contributions: all authors equally contributed to this article.

Conflict of interest: the authors declare no potential conflict of interest.

Funding: part of this work was supported by AGER project, grant $\mathrm{n}^{\circ} 2011-$ 0280 .

Received for publication: 2 December 2015.

Revision received: 23 February 2016

Accepted for publication: 26 February 2016.

@C Copyright E. Pascotto et al., 2016

Licensee PAGEPress, Italy

Geospatial Health 2016; 11:436

doi:10.4081/gh.2016.436

This article is distributed under the terms of the Creative Commons Attribution Noncommercial License (CC BY-NC 4.0) which permits any noncommercial use, distribution, and reproduction in any medium, provided the original author(s) and source are credited.

\section{Introduction}

The ability to create risk maps with respect to the anatomic location of lesions in organs can be an important tool for the identification and diagnosis of several diseases. Geographic information system (GIS) in the format of computer software tools constitutes a powerful approach to store, analyse and manage epidemiological data. Although GIS is mainly applied for the investigation of the localisation and distribution of cases of various diseases in the environment, it can also be used for the positioning of pathology of organs in the body, as described by Daraban et al. (2014), Pascotto et al. (2014), and Imanieh et al. (2015). The aim of present investigation was to determine the topographic distribution of gastritis lesions in pigs through the application of open source GIS software. The research has a practical impact because pigs are sensitive with regard to damage of the gastric mucosa (due to stress and feeding practices) and are considered a suitable animal model for a similar approach in human medicine (Malfertheiner and Ditschuneit, 2011).

The topographic approach to gastritis in human medicine has generally used a regional approach by focusing on the involvement of different areas of the stomach (Hebel, 1949). Thereafter, the topographic analysis of gastritis has progressively specialised by using a sectors and points approach, eventually developing into the modern systems described as the Sydney System (Dixon et al., 1996) or the Operative Link for Gastritis Assessment (Rugge and Genta, 2005). However, accurate research using major search engines of abstracts highlights a limited use of the topographic approach to the description and localisation of gastritis lesions, both in human and animal medicine.

\section{Materials and Methods}

The stomachs of 146 Italian heavy pigs (Italian Large WhitexDuroc Italian) were collected at slaughter and subjected to a macroscopic pathological examination with the aim of detecting internal mucosa damage. For manipulation of the stomachs and analysis, the methodology described by Mason et al. (2013) was followed with use of histopathology to evaluate questionable lesions. Each pathological relief was recorded and characterised based on its macroscopic aspect and extension, then identified with regard to its topographical limits and reported in a georeferenced original map of the stomach internal mucosae. The lesions referred to as gastritis were classified giving them a score of intensity from 1 (mild lesion) to 5 (severe gastritis) and gathered into four categories (Marcato, 2002): i) hyperplastic: mucosa thickened and covered with mucus; ii) follicular: gray-whitish mucosa with swollen lymphatic follicles; iii) atrophic: mucosa having a flattened epithelium, fewer folds or none at all, plus increased connec- 
tive tissue; iv) simple: superficial inflammation of the lamina propria, which is sometimes replaced by connective tissue with no presence of lymphoid follicles. The characteristics and localisation of each lesion were collected into a specific, relational Web-based database, created using open-source software that included the Linux Ubuntu v. 10.10 operating system (http://www.ubuntu.com/); the MySQL AB, v. 5.1 (https:/www.mysql. com/) relational management system for creation of the database; a user-friendly graphical interface obtained from a Web application framework (Symfony ${ }^{\mathrm{TM}}$ v. 1.2.4; SensioLabs, Clichy, France) written in PHP, a server-side scripting language designed for Web development; an Apache HTTP Web Server v. 2.2 (https:/httpd.apache.org/); and a GIS platform integrated into the Web database (GeoServer v. 2.0, http:/geoserver.org/; and OpenLayers library v.2.0, http://openlayers. org/). In order to identify spatial patterns, hotspots and clustering of lesions, data were processed in an open-source GIS software $\left(\mathrm{QGIS}^{\odot}\right.$ 2015; OSGeo, Beaverton, OR, USA) by the following two algorithms. First, Adjust $n$ point to polygon (Adjust $n$ point to polygon ${ }^{\odot} 2015$; Victor Olaya), through which a new point layer was created with a given number of points added inside the area covered by each lesion and distributed over a regular grid. The number of points for each lesion (relative frequency) was determined by multiplying the lesion area $\left(\mathrm{cm}^{2}\right)$ with the score of intensity and a constant (useful to correct possible inaccuracies related to the definition of lesion margins). Second, Kernel density estimation (Anderson, 2009), which was applied to the shapefile containing lesions converted to point format. The kernel bandwidth (search radius), specifying the area around a point where its influence is felt, was $9.7 \mathrm{~cm}$. Based on this value, core areas that included the highest number of injuries were defined and used to calculate: i) the area of injuries; ii) the number of injuries intersecting the core area; and iii) the average weighted intensity inside and outside the core area by the Wilcoxon-Mann-Whitney test (R Core Team, 2015).

\section{Results}

The pigs under investigation had previously been used in three different feeding trials (Zanfi et al., 2014; Capraro et al., 2014; Galassi et $a l ., 2016)$ and were fed diets containing fibrous feeds (whole-ear corn silage and corn silage, from 15 to $40 \%$ of dry matter) or traditional
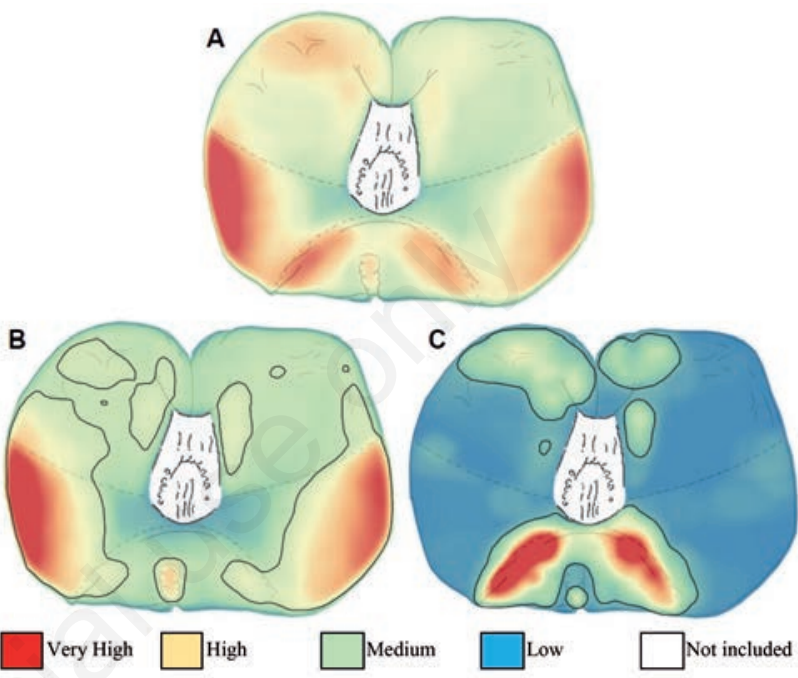

Figure 1. Density maps of gastritis in pigs. A) Relative frequency of total gastritis identified $(n=623)$; B) relative frequency and core areas of the hyperplastic gastritis $(n=406)$; C) relative frequency and core areas of the follicular gastritis $(n=199)$.

Table 1. Pig body weight at slaughter, stomach and gastritis characteristics.

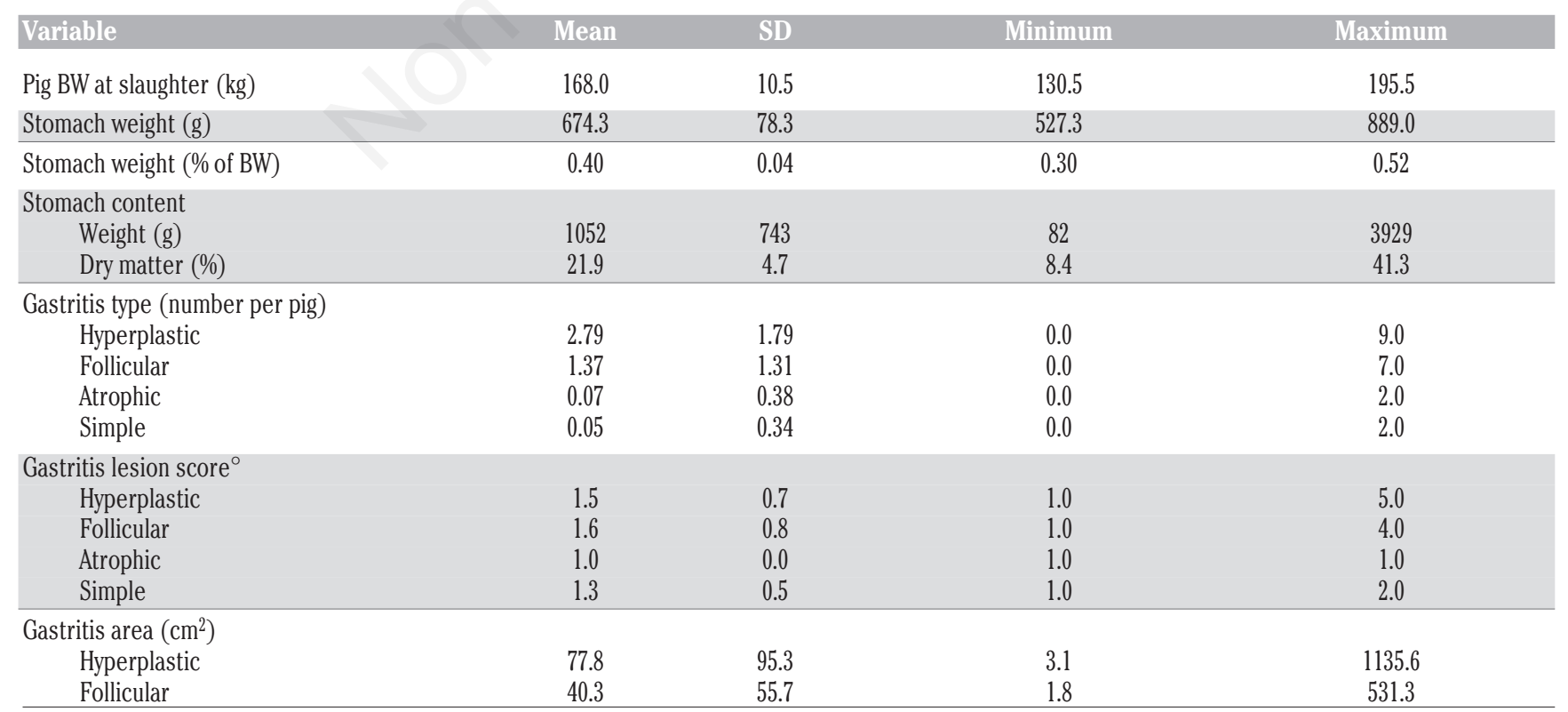

SD, standard deviation; BW, body weight. Varying from 1 (mild lesion) to 5 (severe gastritis). 
corn-soya meal based diets during the last fattening period [ from 80 to $160-170 \mathrm{~kg}$ body weight (BW) ]. Animals were slaughtered (Table 1) at the typical weight adopted in Italy for the production of cured ham prosciutto (160-170 kg BW).

The stomachs represented about $0.40 \%$ of the BW at slaughter (Table 1) and the amounts of gastric contents varied strongly depending on the diets used and the different periods of fasting pre-slaughtering. The examination of individual stomachs revealed a total of 623 lesions (Table 1 and Figure 1A), which were mainly classified as hyperplastic or follicular (97\%), with atrophic and simple gastritis representing a marginal part of the total. There were also differences with respect to the degree of severity of mucosal damage, with the hyperplastic and follicular lesions showing an ample range of variation of the lesion scores with average score values higher than those ascribed to the other gastritis types. The core areas were only defined in hyperplastic and follicular gastritis and intercepted $98.5 \%$ (400/406) and 95.5\% (190/199) of the lesions, respectively. Kernel density and core area analysis showed that hyperplastic gastritis was primarily found within a single oval-shaped area located in the fundus region near the Curvatura ventriculi major (Figure 1B). Some minor parts of this area also extended into the cardiac and the pyloric regions. Hyperplastic gastritis occupied an average area of $77.8 \mathrm{~cm}^{2}$ (6.8\% of the average area of the examined stomachs). The core area (that occupied $44 \%$ of the average area of the examined stomachs) included $61.9 \%$ of the damaged areas. Follicular gastritis was concentrated in the pyloric mucosa, primarily on the edge of the fundus area (Figure 1C). The kernel maps showed two distinct, small areas of high relative frequency, symmetrically localised with respect to the mid-sagittal plane of the organ. Compared to the hyperplastic lesions, the average area of follicular injuries was smaller $\left(40.3 \mathrm{~cm}^{2}\right)$ and covered $3.5 \%$ of the average area of the examined stomachs. They were more concentrated considering that the core area (that was $32.2 \%$ of the average area of the examined stomachs) included $64.1 \%$ of damaged areas of the stomachs. Finally, the Wilcoxon-Mann-Whitney test showed that hyperplastic gastritis was more intense when affecting the core area compared to areas outside it $(1.70$ vs 1.51 ; $\mathrm{P}<0.001)$.

\section{Discussion}

The aim of present work was to describe the localisation and distribution of different gastric mucosal lesions without investigating the aetiology and relationships among different types of lesions. The GIS analysis allowed the production of detailed maps of the internal stomach surface, which highlighted differences in the distribution and concentration of the lesions in most cases of gastritis found. The hyperplastic type of gastritis was widespread over the stomach inner surface, with large lesions mainly localised in the fundus and cardiac areas, with the follicular type less widespread and restricted to the pyloric mucosa. The analysis showed a clear clustering of the distribution of gastric lesions, especially for the hyperplastic gastritis. The localisation of the different lesions was felt to be due to mechanical stress exerted by the feed mass and the distribution of the different glandular types, as well to other factors not yet investigated.

\section{Conclusions}

The use of GIS for the mapping of lesions in internal organs introduces a novel approach, which represents an improvement in comparison with other databases used for the collection of clinical data. The creation of density maps of the relative frequency of gastritis lesions can facilitate the forming of new insights about the possible relationship among the different types of gastritis, their severity, position and aetiology. The results are potentially transferable to human medicine, as the pig is widely used as an animal model. Moreover, information given by the present results may allow targeted sampling of stomach tissue for large-scale inspections in the abattoirs to detect gastric mucosal damages as indicators of pre-slaughter animal welfare.

\section{References}

Anderson TK, 2009. Kernel density estimation and K-means clustering to profile road accident hotspots. Accident Anal Prev 41:359-64.

Capraro D, Zanfi C, Bassi M, Pascotto E, Bovolenta S, Spanghero M, 2014. Effect of physical form of whole ear corn silage (coarse vs wet milled) included at high dietary levels (30 vs 40\% dry matter) on performance of heavy finishing pigs. Anim Feed Sci Technol 198:271-8.

Daraban C, Murino C, Marzatico G, Mennonna G, Fatone G, Auletta L, Miceli F, Vulpe V, Meomartino L, 2014. Using geographical information system for spatial evaluation of canine extruded disc herniation. Geospat Health 9:213-20.

Dixon MF, Genta RM, Yardley JH, Correa P, 1996. Classification and grading of gastritis. The updated Sydney system. Am J Surg Pathol 20:1161-81.

Galassi G, Malagutti L, Rapetti L, Crovetto GM, Zanfi C, Capraro D, Spanghero M, 2016. Digestibility, metabolic utilization and effects on growth and slaughter traits of diets containing corn silage for heavy pigs. Ital J Anim Sci (in press).

Hebel RMD, 1949. The topography of chronic gastritis in otherwise normal stomachs. Am J Pathol 25:125-41

Imanieh MH, Goli A, Imanieh MH, Geramizadeh B, 2015. Spatial modeling of colonic lesions with geographic information systems. Iran Red Crescent Med J 17:e18129.

Malfertheiner P, Ditschuneit H, 2011. Helicobacter pylori, gastritis and peptic ulcer. Springer-Verlag Berlin, Germany.

Marcato PS, 2002. Sistema gastroenterico e peritoneo. In: Marcato PS, ed. Patologia sistematica veterinaria. Edagricole, Bologna, Italy, pp 611-743.

Mason F, Pascotto E, Zanfi C, Spanghero M, 2013. Effect of dietary inclusion of whole ear corn silage on stomach development and gastric mucosa integrity of heavy pigs at slaughter. Vet J 198:717-9.

Pascotto E, Tomè P, Comazzi S, Marco G, Cornegliani L, 2014. Use of an opensource Geographic Information System-based method for topographic analysis of nodular cutaneous lesions in dogs. Vet Dermatol 25:55-60.

R Core Team, 2015. R: a language and environment for statistical computing. R Foundation for Statistical Computing, Vienna, Austria.

Rugge M, Genta RM, 2005. Staging and grading of chronic gastritis. Hum Pathol 36:228-33.

Zanfi C, Colombini S, Mason F, Galassi G, Rapetti L, Malagutti L, Crovetto GM, Spanghero M, 2014. Digestibility and metabolic utilization of diets containing whole ear corn silage and their effects on growth and slaughter traits of heavy pigs. J Anim Sci 92:211-9. 